\title{
Rodríguez Castillo, Luis, Sergio Enrique Hernández Loaeza y María del Carmen Ventura Patiño (coords.) (2014). Democracia, cultura política y ciUdadanía en el MÉxICO DE HOY. MÉXICO: PROIMMSE-IIA-UNAM.
}

\author{
Jesús Solís-Cruz
}

$\mathrm{D}$ os poderosas ideas se encuentran en el centro del concepto de ciudadanía: libertad e igualdad. Con base en ellas, naciones emergentes dieron origen a Estados, y donde estos tenían fortaleza y presencia, se construyeron naciones. En todo el proceso, emergieron nuevos sujetos políticos que gradualmente, de entonces hasta hoy, han pugnado por borrar las líneas del círculo concéntrico en que figuró en sus orígenes la ciudadanía. La ciudadanía es igualmente un concepto caro a la democracia, y ambas son, desde los tiempos modernos, inescindibles. En esta unión hay, sin embargo, una relación conflictiva que tensa los alcances y propósitos de ambas ideas-fuerza, pues la ciudadanía tiene de suyo la búsqueda de la libertad y la igualación de la condición social, mientras que la democracia moderna, por su condición histórica burguesa, se ha visto imposibilitada no sólo de alcanzar el ideal de difundir y ampliar el poder político, sino de generar parámetros equitativos e inclusivos de las posibilidades de vida. Hay allí un problema de orden político y social.

El libro Democracia, cultura política y ciudadanía en el México de hoy, coordinado por Luis Rodríguez, Sergio Enrique Hernández y Carmen Ventura, afronta ese problema. Con la contundencia de los datos sobre altos índices de pobreza y exclusión y sobre la desconfianza institucional en México, el libro pone sobre la mesa de discusión los límites y alcances de la democracia formal. Aporta elementos para mostrar el desencuentro entre las llamadas democracia procedimental y democracia social.

Aun cuando la competencia partidaria y la alternancia política son prácticas corrientes en los juegos del poder político, y las instituciones garantes de estos procesos y procedimientos han logrado cierta legitimidad en nuestro país, las condiciones sociales y culturales en que éstas ocurren no hacen más que contestarlas contundentemente.

En el anterior planteamiento deviene clave el concepto de cultura, porque no es posible entender, y en tal medida avanzar, en proyectos de democracia si no atendemos la "politicidad": el contenido y la práctica política que da sustancia a la democracia y a la ciudadanía. De allí que, para los autores de este libro, resulte central otro concepto clave: el de cultura política.

Con el horizonte problemático antes referido, los autores hacen un despliegue analítico y reflexivo interesante en cuatro grandes apartados. El primero refiere a la democracia y a la ciudadanía en el contexto del neoliberalismo económico y del despliegue de formas de control y autocontrol político bajo la doctrina del "amigo-enemigo".
Jesús Solís Cruz. Centro de Estudios Superiores de México y Centroamérica de la Universidad de Ciencias y Artes de Chiapas. Correo electrónico: soliscruzl@hotmail.com.
Recibida: 18 de marzo de 2016. 
El segundo trata sobre la cultura política para problematizar los postulados básicos subyacentes en las políticas públicas en México. El tercero remite a la conflictiva relación del Estado nacional mexicano con los pueblos originarios y a sus históricas tensiones, pero también a sus novedosas interrelaciones.

La cuarta parte nos presenta las novedosas experiencias autoorganizativas de mujeres que devienen en resistencia ante regímenes patriarcales y paternalistas, trazadas estas resistencias desde la reflexividad de los propios sujetos a partir de su condición de género y etnicidad. De igual modo, se analiza uno de los desafíos contemporáneos más grandes que los Estados nacionales enfrentan: la correlación entre movilidad transterritorial - migración transnacional - ciudadanía y democracia. Es decir, el problema de la soberanía territorial y la definición nacional de ciudadanía en un mundo de intensa movilidad de personas y bienes.

Todos los capítulos que integran el libro sostienen sus reflexiones y análisis en casos concretos, lo que da valor antropológico y sociológico a la obra. Esta condición casuística, analítica y teóricamente reflexiva de los trabajos permite además ampliar y enriquecer la comunicación con las disciplinas que de antaño se han ocupado del tema político, pienso concretamente en la ciencia y filosofía política.

En este sentido, no es contingente que el libro abra con un capítulo en el que el tema de la "acción pública contenciosa" - una idea clave en la teoría política - sea un elemento fundamental para discutir los temas de democracia y ciudadanía. El trabajo sobre la Asamblea Popular de los Pueblos de Oaxaca, de Francisco Javier Gómez Carpinteiro, muestra cómo el movimiento social —o los movimientos sociales — es un importante recurso para ensanchar las nociones de la democracia y la ciudadanía en México. El protagonismo de los actores movilizados, valiéndose de recursos contenciosos del pasado, deviene fundamental para activar o reactivar las memorias políticas de los ciudadanos y, en esa medida, propiciar la apertura de otros ciclos democráticos populares, situándose incluso como "expresiones políticas incómodas" para lo que desde la oficialidad se nombra como ciclo democrático. La expresión políticamente incómoda que toma este tipo de acciones contenciosas genera y activa a la vez acciones adversas del régimen que, por métodos incluso muy sutiles — como la opinión pública o la voz popular-, se trasladan a la sociedad más amplia. Y en este trazo de espacio público en el que interaccionan los sujetos movilizados y el Estado, se promueven formas de gobernar la conciencia y las acciones de los sujetos cifradas sobre representaciones dualistas del bien o el mal. Lo que resulta de lo anterior, según Gómez Carpinterio, es un campo de disputa en el que la democracia es un recurso de gran importancia para los contendientes.

La democracia, en ese sentido, es eminentemente contestable y se encuentra en permanente construcción, postulado que aplica también para la ciudadanía; por ello, como ha señalado Claudio Lomnitz en su libro Deep Mexico, Silent Mexico. An Anthropology of Nationalism, editado en 2001 por la Universidad de Minnesota, la ciudadanía - yo agregaría la democracia - no puede ser considerada como el grado cero de las relaciones sociales y políticas porque la valoración que de la misma resulte será implacablemente desalentadora.

Esta consideración está presente en el trabajo de Luis Rodríguez sobre políticas públicas. Con un interés de tipo teórico-metodológico, Rodríguez traza una novedosa ruta crítica sobre los estudios y enfoques de las políticas públicas para proponer otra en la que tenga lugar, además, la dimensión cultural de lo político. Da en esa medida un aporte valioso al área de conocimiento de la ciencia política y la administración pública al buscar "antropologizar" estas áreas de conocimiento tan especializadas. No es meramente discursivo decir que Rodríguez antropologiza la ciencia política y la administración pública como discursos académicos, pues lo que él busca es justamente situar la dimensión de lo humano, lo contingente y localizado de las acciones de los sujetos sociales. Dice a ese respecto: "toda institución, toda política pública, independientemente de su naturaleza técnica, coercitiva o aparentemente impersonal, sólo será efectiva y generará acción pública si se relaciona con los asideros utópicos, rituales y simbólicos establecidos en una sociedad compleja" (72). 
Hay en esta propuesta un posicionamiento de orden teórico y metodológico innovador y pionero.

Emmanuel Rodríguez, recuperando justamente la anterior propuesta, problematiza sobre las acciones cívicas y clientelares que se propician en la instrumentación de programas sociales. Tomando como caso las políticas públicas con carácter bienestarista social implementadas en la delegación Cuauhtémoc, en la ciudad de México, este autor, con base en trabajo de campo, muestra la conformación de un espacio público complejo en el que interactúan promotores y agentes de políticas sociales con ciudadanos destinatarios de las mismas. Esa interacción, parece conceder el autor, no es posible caracterizarla de una sola vez, pues las acciones de los sujetos son tan diversas que en ciertos momentos en una misma acción parecen coincidir reivindicaciones de orden cívico con prácticas clientelares.

Aún más, existen discursos con ideas libertarias e igualitarias - propiamente ciudadanas- que perviven con acciones corporativas y clientelares. Esta complejidad, a la vista del autor, mina lo que, sin él declararlo, "debe ser" una democracia y una ciudadanía pues las categoriza como "prácticas regresivas a la democracia".

Las reflexiones y análisis más destacados sobre ciudadanía en México han sostenido que, en el origen del Estado nacional mexicano independiente, las élites políticas - sin distinción de programa e ideologíamostraron cierto desdén por la legalidad, y en ese mismo sentido, desestimación a la ciudadanía, categoría en la que se sintetizan nociones de legalidad individual y colectiva. Se plantea como hipótesis que el apremio por la creación de un Estado central y fuerte opacó el obsesivo lenguaje legal y de ciudadanía del comienzo de la vida independiente de la nación mexicana, y una vez que lo primero se consiguió, se dio prioridad al discurso de orden y al progreso material, lo que aplazó la formación de una ciudadanía activa en México.

El mismo derrotero se siguió en la fase postrevolucionaria, cuando incluso se generaron, en el marco de la formación del nuevo Estado y el Gobierno de partidoúnico, prácticas políticas que privilegiaron el corporativismo y el arreglo fuera de la ley. A resultas de lo anterior, lo que hemos tenido en México ha sido una ciudadanía masificada y "de baja intensidad" tutorada fundamentalmente por el Estado. Incluso se sostiene que, cuando el Estado y el Gobierno de partido único entraron en crisis hacia finales de la década de 1980, sumado a la orfandad de patronazgos privados y a la insuficiencia de posesiones privadas, la ciudadanía se vio en el desamparo. Aunque se puede convenir en cierto punto con estas lecturas de hegemonía estatal, me parece importante matizar, para dar cabida a sujetosactores políticos, que han actuado políticamente para interpelar o promover derechos de ciudadanía, frente o al margen del Estado, principalmente por la vía de la acción pública contenciosa.

Los sujetos de estudio en los capítulos de Carmen Ventura, Emmanuel Nájera y Sergio Enrique Hernández muestran justamente lo anterior.

Carmen Ventura, en su análisis sobre "Democracia y ciudadanía en la meseta purhépecha de Michoacán", devela cómo sujetos desplazados incluso de la condición de ciudadanos, gradualmente y por impulso del autorreconocimiento de sí mismos como sujetos políticos -étnicamente hablando-, van ganando presencia pública en las distintas esferas de la vida, hasta impactar y conseguir el control del poder político local. En este proceso resulta central la socialización política mediante la forma electoral, que luego es contestada en sus formas y prácticas para transitar a novedosas maneras de autogobierno, un proceso en el que se desestructuran marcos de interacción social y políticos montados sobre criterios de raza y clase.

El capítulo de la autoría de Emmanuel Nájera trata justamente sobre la imbricación entre ciudadanía y etnicidad. Retomando el caso de la conformación de la administración municipal de San Cristóbal de Las Casas, Chiapas, en el periodo de emergencia y pos emergencia del neozapatismo, Nájera muestra el difícil tránsito del reconocimiento de la etnicidad — como condición subjetiva y política - en un entorno dominado precisamente por discursos y prácticas de raza y clase. En su minucioso estudio, el autor pormenoriza las correlaciones políticas internas y externas, apegadas a lo formal e informal, que fueron posibilitando la 
inclusión — regularmente desventajosa - de actores y agentes indígenas en la vida pública sancristobalense. Sin embargo, dice el autor, esta inclusión desigual no ha garantizado la participación real en la arena políticoelectoral ni en la administración pública local, lo que significa que no hay un empoderamiento de la población indígena en la administración local, como en el discurso cotidiano se dice, sino que, por el contrario, Nájera señala caminos desiguales de participación.

El capítulo de la autoría de Sergio Enrique Hernández aborda la conformación municipal y la lucha que en torno a un caso se desarrolló en la sierra de Puebla. A partir de revisar el caso de la comunidad de San Juan Ozelonacaxtla, desde una perspectiva histórica, el autor nos muestra la compleja interrelación entre formación de soberanías locales y Estado nacional. Muestra cómo la conformación de gobierno es un proceso de permanente contestación y en él se involucran actores con intereses particulares de dominio y control orientados a una supuesta centralidad política o revocados hacia lo local. De particular relevancia en este intento de generar gobierno en estos espacios resultan los cacicazgos como mediadores y operadores políticos. Estas formas de mediación pueden en algunos sentidos posibilitar integraciones amplias y duraderas con el resto de la sociedad nacional, o anularlas. Resulta relevante metodológicamente, en todo caso, entender estos procesos, pues en su comprensión, según el autor, pueden encontrarse las claves para pensar formas de ciudadanía que ponderen la condición cultural, como ocurre en el caso analizado.

Cierran el libro los trabajos de Práxedes Muñoz y José Carlos Luque. El capítulo de Práxedes Muñoz se ocupa de experiencias autoorganizativas en colectivos de mujeres de Tabasco. Desde un posicionamiento de antropología comprometida con los sujetos de la investigación, Muñoz se sitúa como co-participe y colaboradora en la estructuración de acciones concretas tendientes a incidir en la realidad social. Muestra el proceso de conversión de la misma antropóloga en su contacto con la realidad y la teoría y metodología participativa que utilizó, al tiempo que recorre la experiencia de las mujeres actuantes en las formas organizativas impulsadas. Hay en esta descripción y conversación que la antropóloga sistematiza, muestras de formación de nuevas subjetividades, alentadas por el reconocimiento de la condición de género y de etnia. Es en tal sentido una experiencia de formación de nuevas ciudadanías.

El capítulo de JoséCarlos Luque, "Transnacionalismo, migración, ciudadanía y democracia”, trata, como ya he mencionado, sobre uno de los mayores desafíos contemporáneos que los Estados nacionales enfrentan: la correlación entre movilidad transterritorial — migración transnacional-, ciudadanía y democracia. Es decir, el problema de la soberanía territorial y la definición nacional de ciudadanía en un mundo de intensa movilidad de personas y bienes. Toca en algún punto la paradoja de la libre circulación de bienes transnacional y la restricción de la movilidad humana, y abre también puntos de debate sobre un problema inherente a la misma ciudadanía, el de la exclusión, y, aún más, el punto lleva a reflexionar sobre la calidad de la inclusión. Se es ciudadano de qué estado nacional o residente de... y en esto se define la calidad de ciudadanía. Frente a esto, hoy quela geopolítica se ha reorganizado por acontecimientos como el ll de septiembre de 2001 en Estados Unidos, los Estados nacionales se han visto obligados a revisar sus nociones de ciudadanía separando incluso esta idea de la de nacionalidad. La movilidad transnacional, dice el autor, obliga a repensar conceptos nodales, tales como Estado y nacionalismo.

Para concluir, quiero señalar que, en tiempos recientes y en el contexto global y de ascenso de reclamos de derechos culturales y diferenciados, la noción de ciudadanía, que en su evolución llegó a definirse como universal y neutral ante las diferencias de tipo social, cultural y religiosa, está hoy siendo cuestionada por considerarse lesiva de los derechos de colectivos sociales - háblese de pueblos originarios, de grupos nacionales o en situación transnacionalSin embargo, creo también que el vigor de la noción de ciudadanía, y en consecuencia del de democracia, como lo muestran los diversos trabajos en este libro, reside en que es en sí misma una hipótesis, un proyecto que 
tiene como particularidad un carácter inacabado y, en consecuencia, de permanente reconfiguración

Es en todo caso un concepto "bueno para pensar" o seguir pensando sobre temas acuciantes y sobre los desafíos por venir. Hasta hoy el mayor de éstos ha sido el de la igualdad. Aunque se impulsó y difundió discursivamente el principio de igualdad universal en México, su concreción devino en un problema, ante una realidad social, económica y política contrastantemente desigual. Éste fue un dilema al que se enfrentaron las élites ilustradas decimonónicas, impulsoras de las revoluciones burguesas independentistas. El mismo problema figuró en el período de posguerra, en el contexto de la formación del Estado social. Hoy sigue siendo el mayor desafío, y de ello se ocupa este libro. Es entonces, como dicen los coordinadores de este libro, necesario hablar, pensar y actuar sobre la democracia, pues en esa medida se podrán propiciar la igualdad jurídica, la igualdad política y la igualdad social. Y quizás debamos hacerlo en los contornos de la política y lo político, pues la política es el camino para la transformación del individuo. 